Peter H. Schwartz. The value of information and the ethics of personal-genomic screening. Am J Bioeth. 2009 Apr;9(4):26-7. [ Preprint. Final version available online at: http://dx.doi.org/10.1080/15265160802716878 ]

\title{
The Value of Information and the Ethics of Personal-Genomic Screening
}

Peter H. Schwartz, MD, PhD

Indiana University Center for Bioethics

1.

Burger and Kass argue that doctors should avoid ordering screening tests in most cases where there are no professional guidelines or where guidelines discourage the use of the test (class D recommendation) (Burger and Kass, in press). Examples of unproven screening tests include whole-body CT scanning in healthy individuals and brain MRAs in patients with a family history of aneurysms. Burger and Kass claim that it is unethical to order such tests partly since patients requesting them may be unaware of the risks and the uncertainties about them (p.17). Ordering such a test also diverts healthcare resources from more effective uses, increases the chance that the test will become "standard of care," and undermines the ability of researchers to recruit subjects for randomized studies of it (p. 21). Even if the risk of the test is small, false positives or incidental findings can lead to more risky and expensive tests and treatments, which again may cause no benefit and even net harm. For all these reasons, the authors take a firm position against the use of unproven screening tests (under "Case 1" and "Case 2") (Burger and Kass, in press).

The most serious challenge to Burger and Kass’s position involves the possibility of a patient who fully understands the possible risks and unclear benefits, is willing to shoulder the expense personally, and greatly values the reassurance that a negative test could provide. The authors acknowledge that there could be such a case, involving a test with minimal supporting evidence, where the "physician actually believes the benefits of screening could outweigh the harms for a particular patient” (p. 19). But even then, they argue, the physician should resist the patient's entreaties (p. 19).

They state the crux of their argument as follows: "The primary goal of medicine, including the administration of medical services, is to benefit patients' health. As such, patients should not have free access to any medical test or treatment they desire and can pay for, as they would for other types of goods and services. Indeed, physicians should actively protect them from medical products of poorly quantified risks and benefits.” (p. 19) The key principle here appears to be that the doctor should only offer interventions that she believes will (or may) have 
a net benefit for the patient's health, and should refuse to offer services that she believes will offer only reassurance or solace, not improved health.

This principle has been more typically used in discussions of decisions regarding treatment, rather than testing. For example, a doctor may ethically refuse to provide a medication or procedure that she believes will not benefit the patient, no matter how much the patient desires the treatment and understands the issues. But there can be significant questions about this principle, especially if the treatment has low risk and could have very positive psychological effects. Solace, after all, is a reasonable goal of healthcare as well as health, as has been accepted in palliative care and pain management.

The principle is even more problematic when considering tests rather than treatments. Although tests must be evaluated primarily based on their ability to improve outcomes, the information provided by testing may be valuable in itself, for example when it carries prognostic implications. Knowledge may be pursued independent of any practical import in other areas as well, such as basic science. The key dangers of unproven tests are their consumption of precious healthcare resources and tendency to lead to other unbeneficial, high-risk, and high-cost tests and treatments (Redberg and Walsh 2008). That said, it may be only fair to allow patients to choose to undergo low-risk tests that they can pay for themselves, as long as they understand the facts and want the information. The proper stopping point may be after the initial testing, before embarking on further, higher-risk tests or treatments.

2.

The recent introduction of "personal-genomics” screens in clinical care provides an important setting in which to apply and extend Burger and Kass's arguments. Multiple companies now offer tests that survey an individual's genome to identify single-nucleotide polymorphisms (SNPs) and then provide information - often very tentative - about associated characteristics and medical risks. The company 23andme provides customers with information on 96 topics, ranging from their risk for diabetes, heart disease, and multiple cancers to their type of earwax and sensitivity to bitter taste (https://www.23andme.com/). Other companies, such as Navigenics (http://www.navigenics.com/) and deCODEme (http://www.decodeme.com/) focus more specifically on medical risks (Fox 2008, Salkin 2008). 
The information provided by such companies is based on studies - of more or less validity and reliability - of associations between specific SNPs and individuals' risks and characteristics (Fox 2008). Such genetic information is necessarily partial even if it is valid: a patient with below-average genetic risk of lung cancer may well have higher-than-average overall risk, due to a heavy smoking history. There is basically no evidence at present that these sort of genetic tests contribute to health or improve healthcare. And, like the tests that Burger and Kass discuss, there is also the significant possibility of harm: imagine that the patient who hears that he has below average risk for lung cancer decides that he should not bother quitting smoking. The tests do not fit the definition of "screening” that Burger and Kass adopt - since the goal is to determine risk, not to detect "preclinical disease” (Morrison 1992, quoted in Burger and Kass, p. 9) - but their arguments suggest that doctors should resist patients' requests for personal-genomic analyses.

This recommendation must again confront the possibility of a well-informed patient who wants the information and is willing to pay out-of-pocket for the test. While medicine's goal is to treat the sick and support health, genetic testing can satisfy other reasonable human needs, such as a desire to know. By mixing in data about risk for baldness, muscle performance, and ancestry, 23andme blurs the line between personal and medical information, and thus enhances the argument that it is unjust to withhold the test from all individuals until it is proven useful in medical care.

Taking this reasoning to its logical conclusion, 23andme and Navigenics now offer their testing directly to consumers, accomplishing an end-run around medical authority. Anybody who is willing to pay $\$ 399$ to 23andme, for instance, can fill up a test-tube with his saliva and get the full report (Fox 2008, Salkin 2008). This comes with access to a website that provides lay explanations of the information and various other features, such as an opportunity for social networking among people with similar genetic traits. For pioneering the "retail DNA test," 23andme won Time magazine’s Invention of the Year award in 2008 (Hamilton 2008).

Although such direct-to-consumer testing is limited in some states (Fox 2008), the availability of these tests in many places shifts the question from whether doctors should order the tests to how to respond to them and how to regulate them. At least part of the regulatory model should focus on making sure that consumers are adequately informed before and after they choose to be tested. Providing such information beforehand certainly serves the goal of 
informed consent and may convince many not to purchase personal genomic testing. Burger and Kass propose similar rules for informed consent before unproven screening tests that have at least some evidence of benefit (under Case 3).

Information and education is also key to managing the impact of the tests. A patient who hears that he has "below average” risk of heart disease must also hear that healthy behaviors are still important for him. A patient who learns that he has a slightly elevated risk of prostate cancer should also learn that there is no evidence supporting earlier or more frequent screening for him, and that such testing can lead to invasive and risky testing and treatment. In addition, a patient who wants to pursue unusual screening or treatment should be expected to bear the expense himself.

Healthcare professionals as well need to be provided with clear, evidence-supported guidelines for how to respond to genetic screens. A doctor who is unsure how to treat a patient with a slightly increased chance of heart disease or cancer, for instance, may well respond by over-testing and over-treating. Even if a doctor believes that no response is needed, he may feel motivated to act due to fear of a possible lawsuit if he turns down the patient's request and the patient later develops the disease. Doctors will only be able to resist such pressure if there are clear and easily accessed guidelines.

Personal genomic screening, especially when marketed direct-to-consumers, thus threatens to worsen the inefficient use of healthcare resources that Burger and Kass discuss in the case of unproven screening tests. The information that genomic and other screening tests can provide may well have value for many patients, but its effective use in healthcare depends on careful thought about the ethics of testing and the proper regulation of unproven interventions.

\section{REFERENCES:}

Burger, Ingrid, and Nancy E Kass (in press), "Screening in the Dark: Ethical Considerations of Providing Screening Tests to Individuals When There is Insufficient Evidence to Support Screening Populatinos,” American Journal of Bioethics 
Fox, Jeffrey (2008), “What Price Personal Genome Exploration?” Nature Biotechnology 26, $1105-1108$.

Hamilton, Anita (2008), “1. The Retail DNA Test,” Time Oct. 27, 2008, accessed at http://www.time.com/time/specials/packages/article/0,28804,1852747_1854493,00.html

Morrison, A. (1992), Screening in Chronic Disease. NY: Oxford Univ. Press.

Redberg, Rita and Judith Walsh (2008), "Pay Now, Benefits May Follow - The Case of Cardiac Computed Tomographic Angiography,” New England Journal of Medicine 359; 22: 2309-2311.

Salkin, Allen (2008), "When in Doubt, Spit it Out,” The New York Times, Sept. 14, 2008, Section ST, p. 1. 